\title{
TAVI durability beyond five years: no alarms, but stay alert
}

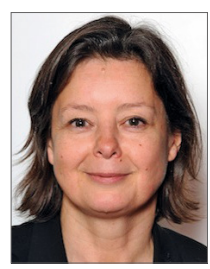

Hélène Eltchaninoff ${ }^{1,2 *}$, MD; Eric Durand ${ }^{1,2}, \mathrm{MD}, \mathrm{PhD}$; Alain Cribier $^{1}, \mathrm{MD}$

1. Department of Cardiology, Rouen University Hospital, FHU REMOD-VHF, Rouen, France; 2. Normandie Univ, UNIROUEN, INSERM U1096, Rouen, France

Transcatheter aortic valve implantation (TAVI) has been widely adopted for the treatment of severe symptomatic aortic stenosis in elderly patients. Alain Cribier's crazy concept of non-surgical valve implantation was to offer a life-saving treatment to the thousands of symptomatic patients with aortic stenosis who could not be operated on because of age and/or comorbidities ${ }^{1}$. His dream has come true. With the impressive continuous improvement in results, the technique is now the treatment of choice in elderly patients with few comorbidities and favourable transfemoral access. The evidence surpasses expectations: TAVI offers even better results than surgery for up to two years in lower-risk elderly patients. The next step will be to demonstrate that TAVI is the default strategy in all patients over 65 years. Several large randomised trials are currently evaluating TAVI in this indication. In this context, long-term durability has become a topic of major interest among the scientific community: is the durability of TAVI comparable to that observed with surgical valves? Today, the only available randomised data are limited to the five-year outcomes from the PARTNER trial and are reassuring ${ }^{2}$.
Interestingly, the performance of a surgical bioprosthesis is commonly assessed by the need for reintervention. This is a poor surrogate for structural valve deterioration (SVD) as reintervention can be performed for reasons other than SVD, may not be performed if SVD goes undetected and some patients are too old to undergo repeat surgery despite severe SVD. Therefore, the endpoint of reintervention would probably underestimate the rate of SVD.

For all these reasons it has become urgent to harmonise the definition of SVD. A European Society of Cardiology/European Association for Cardio-Thoracic Surgery statement ${ }^{3}$ published in 2017 and a recent consensus document from the VIVID group ${ }^{4}$ provide important standardisation for trials focusing on long-term durability and late outcomes. In parallel, data on durability beyond five years are emerging with very recent first publications on late outcomes $^{5,6}$.

In this issue of EuroIntervention, Holy et al publish: "Longterm durability and haemodynamic performance of a self-expanding transcatheter heart valve beyond five years after implantation:

*Corresponding author: Department of Cardiology, Charles Nicolle Hospital, 1 rue de Germont, 76031 Rouen Cedex, France. 
a prospective observational study applying the standardised definitions of structural deterioration and valve failure" published in two months on long-term durability beyond five years.

\section{Article, see page $\mathbf{3 9 0}$}

One hundred and fifty-two consecutive patients who had undergone TAVI with the self-expanding CoreValve ${ }^{\circledR}$ (Medtronic, Minneapolis, MN, USA) between 2007 and 2011 at the Heart Center, Bad Segeberg in Germany were evaluated. Echocardiographic follow-up was achieved at $6.3 \pm 1.0$ years (5.0-8.9 years) and was $88 \%$ complete (60 out of 68 survivors beyond five years). SVD was assessed using the recent European standardised definitions and echocardiograms were analysed by an independent core laboratory. No case showed evidence of SVD. The rare patients $(5 ; 3.3 \%)$ who had undergone redo TAVI or surgery had paravalvular leakage.

We first reported our series ${ }^{5}$ on durability beyond five years in 378 patients from our first-in-man (2002 to 2012). Our patients were treated with balloon-expandable valves and were followed annually - up to 11 years in one patient (Figure 1). Only two patients $(0.58 \%)$ had reintervention, and nine $(3.2 \%)$ demonstrated SVD (moderate in six and severe in three) using the European consensus definitions. In the May issue of EuroIntervention, Deutsch et $\mathrm{al}^{6}$ reported late outcomes and SVD in 300 patients who had undergone TAVI with first-generation devices between 2007 and 2009. At seven years, $23.2 \%$ of their patients were alive and the cumulative incidence of SVD according to the same European definitions was $14.9 \%$ (self-expanding: $11.8 \%$; balloon-expandable: $22.6 \%$ ).

On the whole, for the only three published series beyond five years, the rate of reintervention for SVD at seven years was very low $(<1 \%)$, which is reassuring even accounting for the low number of patients at risk at seven years (63 patients) in this early compassionate/high-risk population. When assessing SVD using strict echocardiographic criteria (mean gradient: value and increase compared to baseline, central aortic regurgitation), the rate of SVD is variable among the three series, ranging from $0 \%$ in the current paper of Holy et al to $3.2 \%$ and $14.9 \%$ in ours and Deutsch's, respectively, without any clear explanation for these differences. Indeed, all three studies report annual clinical and echocardiographic follow-up, more than $88 \%$ of patients had an echocardiographic examination at the same time as their last follow-up or event, and the period of inclusion was similar for Holy and Deutsch (from 2007) and earlier in our series (from 2002).

Do we have reasons to fear inferior durability to that of surgical bioprostheses as commonly suggested? Hypotheses have
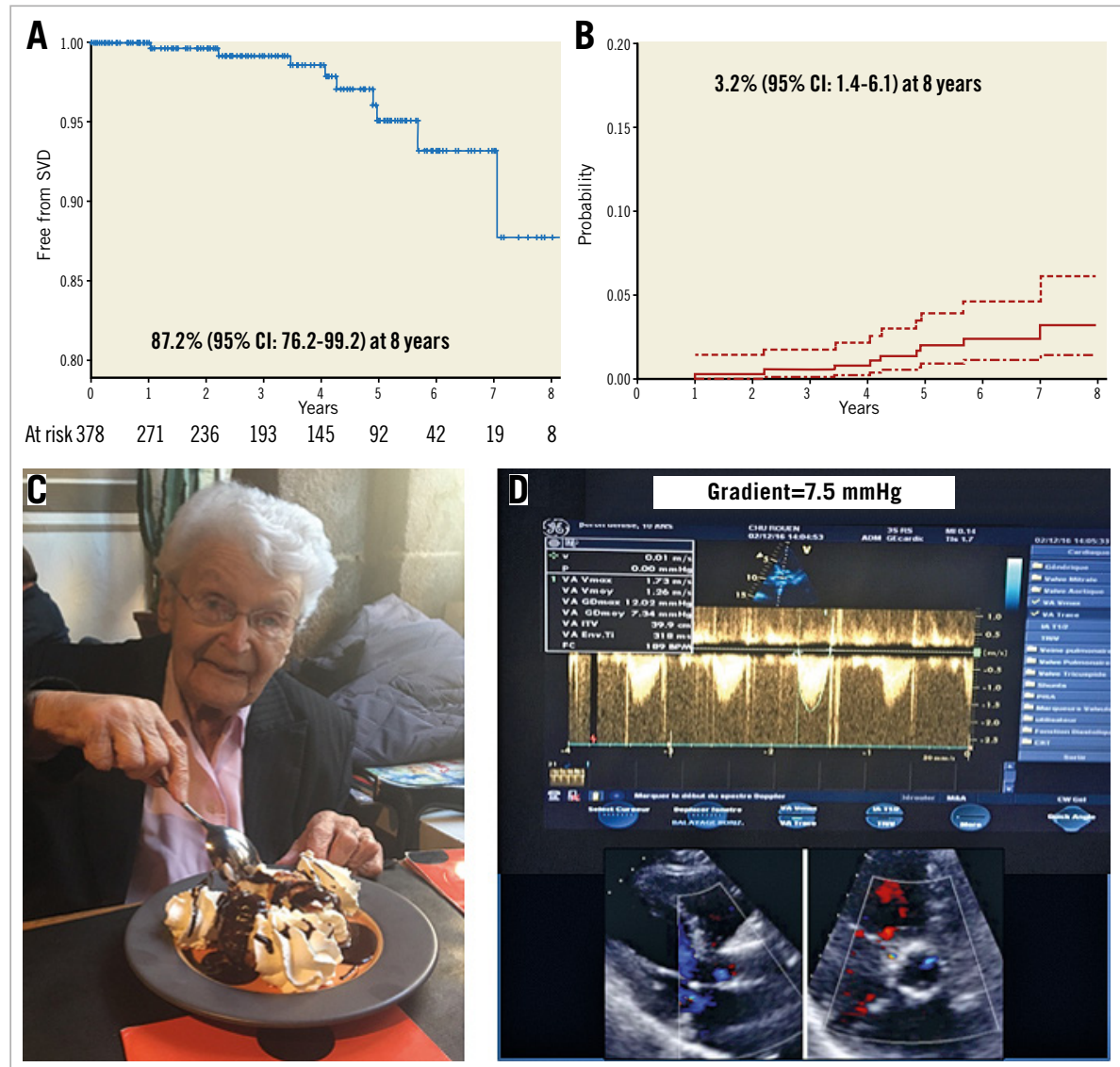

Figure 1. Durability beyond five years. A) Freedom from SVD (Kaplan-Meier analysis). B) Incidence of SVD (death-competing risk analysis)5. C) A 95-year-old female patient celebrating her 10-year anniversary of TAVI with a normally functioning Edwards SAPIEN bioprosthesis (D). 
been raised but concerns have not yet materialised: non-circular expansion of the stent and resulting suboptimal haemodynamics, crimping the leaflets over the balloon, and the use of porcine pericardium could theoretically lead to decreased durability.

It is too early to answer these questions, but it is time to accumulate scientific data and stimulate the medical community to perform annual clinical and echocardiographic assessment for all patients with a bioprosthetic valve and to participate in registries and trials.

Alain Cribier's dream of implanting a valve as a stent-like procedure without resorting to heavy surgery has come true. Moreover, it continues to thrive due to the possibility of acquiring an excellent valve without the invasiveness surrounding surgery. Indeed, the non-invasive nature of TAVI represents a major advantage and, even if inferior durability to surgery is demonstrated in the coming years, it is likely that patients will still choose TAVI as their default strategy, keeping in mind that surgery might be performed later and even be followed by a valve-in-valve procedure, a déjà-vu strategy in myocardial revascularisation.

\section{Acknowledgements}

The authors are grateful to Nikki Sabourin-Gibbs, Rouen University Hospital, for her help in editing the manuscript.

\section{Conflict of interest statement}

H. Eltchaninoff and E. Durand report modest lecture fees from, and A. Cribier is a consultant for Edwards Lifesciences.

\section{References}

1. Cribier A, Eltchaninoff H, Bash A, Borenstein N, Tron C, Bauer F, Derumeaux G, Anselme F, Laborde F, Leon MB. Percutaneous transcatheter implantation of an aortic valve prosthesis for calcific aortic stenosis: first human case description. Circulation. 2002;106:3006-8.

2. Mack MJ, Leon MB, Smith CR, Miller DC, Moses JW, Tuzcu EM, Webb JG, Douglas PS, Anderson WN, Blackstone EH, Kodali SK, Makkar RR, Fontana GP, Kapadia S, Bavaria J, Hahn RT, Thourani VH, Babaliaros V, Pichard A, Herrmann HC, Brown DL, Williams M, Akin J, Davidson MJ, Svensson LG; PARTNER 1 trial investigators. 5-year outcomes of transcatheter aortic valve replacement or surgical aortic valve replacement for high surgical risk patients with aortic stenosis (PARTNER 1): a randomised controlled trial. Lancet. 2015;385:2477-84.

3. Capodanno D, Petronio AS, Prendergast B, Eltchaninoff $H$, Vahanian A, Modine T, Lancellotti P, Sondergaard L, Ludman PF, Tamburino C, Piazza N, Hancock J, Mehilli J, Byrne RA, Baumbach A, Kappetein AP, Windecker S, Bax J, Haude M. Standardized definitions of structural deterioration and valve failure in assessing long-term durability of transcatheter and surgical aortic bioprosthetic valves: a consensus statement from the European Association of Percutaneous Cardiovascular Interventions (EAPCI) endorsed by the European Society of Cardiology (ESC) and the European Association for Cardio-Thoracic Surgery (EACTS). Eur Heart J. 2017;38:3382-90.

4. Dvir D, Bourguignon T, Otto CM, Hahn RT, Rosenhek R, Webb JG, Treede H, Sarano ME, Feldman T, Wijeysundera HC, Topilsky Y, Aupart M, Reardon MJ, Mackensen GB, Szeto WY, Kornowski R, Gammie JS, Yoganathan AP, Arbel Y, Borger MA, Simonato M, Reisman M, Makkar RR, Abizaid A, McCabe JM, Dahle G, Aldea GS, Leipsic J, Pibarot P, Moat NE, Mack MJ, Kappetein AP, Leon MB; VIVID (Valve in Valve International Data) Investigators. Standardized Definition of Structural Valve Degeneration for Surgical and Transcatheter Bioprosthetic Aortic Valves. Circulation. 2018;137:388-99.

5. Eltchaninoff H, Durand E, Avinée G, Tron C, Litzler PY, Bauer F, Dacher JN, Werhlin C, Bouhzam N, Bettinger N, Candolfi $\mathrm{P}$, Cribier A. Assessment of structural valve deterioration of transcatheter aortic bioprosthetic balloon-expandable valves using the new European consensus definition. EuroIntervention. 2018;14:e264-e271.

6. Deutsch MA, Erlebach M, Burri M, Hapfelmeier A, Witt OG, Ziegelmueller JA, Wottke M, Ruge H, Krane M, Piazza N, Bleiziffer S, Lange R. Beyond the five-year horizon: long-term outcome of high-risk and inoperable patients undergoing TAVR with first-generation devices. EuroIntervention. 2018;14:41-9.

7. Holy EW, Kebernik J, Abdelghani M, Stämpfli SF, Hellermann J, Allali A, El-Mawardy M, Sachse S, Lüscher TF, Tanner FC, Richardt G, Abdel-Wahab M. Long-term durability and haemodynamic performance of a self-expanding transcatheter heart valve beyond five years after implantation: a prospective observational study applying the standardised definitions of structural deterioration and valve failure. EuroIntervention. 2018;14:e390-6. 